Check for updates

Cite this: RSC Adv., 2018, 8, 41109

Received 10th October 2018

Accepted 29th November 2018

DOI: $10.1039 / c 8 r a 08402 e$

rsc.li/rsc-advances

\section{Study of catalytic ozonation for tetracycline hydrochloride degradation in water by silicate ore supported $\mathrm{CO}_{3} \mathrm{O}_{4} \dagger$}

\author{
Lisha Luo, (D) ${ }^{a b c}$ Donglei Zou, ${ }^{a}$ Dongwei Lu, (D) *c Fengli Yu, ${ }^{b}$ Bingjing Xin (DD ${ }^{b}$ \\ and Jun $\mathrm{Ma}^{\mathrm{C}}$
}

Tetracycline hydrochloride (TCH) degradation by cobalt modified silicate ore (CoSO) catalytic ozonation in aqueous solution was investigated. CoSO catalyst was synthesized by an impregnation method using $\mathrm{Co}\left(\mathrm{NO}_{3}\right)_{2}$ as the precursor and natural silicon ore (SO) as the support. The key catalyst preparation conditions (i.e., impregnation concentration, calcination temperature and time) were optimized. The activity and stability of CoSO catalyst and its catalytic ozonation mechanism for TCH degradation were studied. The results showed that $\mathrm{CO}_{3} \mathrm{O}_{4}$ was successfully coated on the silicon ore and the CoSO catalyst was highly efficient in catalytic ozonation for $\mathrm{TCH}$ degradation. The $\mathrm{TCH}$ removal by $\mathrm{CoSO} / \mathrm{O}_{3}$ could reach $93.2 \%$, while only $69.3 \%$ by $\mathrm{SO}^{\circ} \mathrm{O}_{3}$ and only $46.0 \%$ by $\mathrm{O}_{3}$ alone at $25 \mathrm{~min}$. The reaction of $\mathrm{TCH}$ degradation followed pseudo-first order kinetics. TOC removal rate by $\mathrm{CoSO} / \mathrm{O}_{3}$ was 2.0 times higher than that by $\mathrm{SO}_{3} \mathrm{O}_{3}$, and 3.5 times higher than that by $\mathrm{O}_{3}$ alone. The reaction conditions $(\mathrm{TCH}$ initial concentration, catalyst concentration, $\mathrm{pH}$ and temperature) for catalytic ozonation were systematically investigated. The possible mechanism for the CoSO catalytic ozonation process was proposed, where hydroxyl radical oxidation mainly accounted for the substantial TCH degradation. Furthermore, CoSO showed great durability and stability after seven reaction cycles.

\section{Introduction}

Tetracycline hydrochloride ( $\left.\mathrm{TCH}, \mathrm{C}_{22} \mathrm{H}_{24} \mathrm{~N}_{2} \mathrm{O}_{8} \cdot \mathrm{HCl}\right)$ is the second most widely used antibiotic for disease control and animal enhancing growth. ${ }^{1}$ It has a stable chemical structure and is difficult to be metabolized completely in the bodies of people or animals. ${ }^{2}$ It enters into wastewater and soil by excreted feces or urine, as pharmaceutically active forms and degradation products. ${ }^{3}$ In addition, due to its poor biodegradability and antibiotic properties, it is difficult for the conventional biological treatment technology to remove $\mathrm{TCH}$ thoroughly. ${ }^{\mathbf{1 , 4}}$ Thus, it accumulates in aquatic environments and leads to the proliferation of antibiotic-resistance genes, disrupts ecosystem function and ultimately harms human health. ${ }^{5}$

Recently, advanced oxidation processes (AOPs) such as ozone, Fenton and photocatalytic oxidation, have been

${ }^{a}$ Key Laboratory of Ministry of Education for Groundwater Resources and Environment, College of New Energy and Environment, Jilin University, Changchun 130000, P. R. China

${ }^{b}$ College of Resources and Environmental Engineering, Jilin Institute of Chemical Technology, Jilin 132022, China

'State Key Laboratory of Urban Water Resource and Environment, Harbin Institute of Technology, Harbin 150090, P. R. China. E-mail: lvdongwei@hit.edu.cn

$\dagger$ Electronic supplementary informations (ESI) available. See DOI: 10.1039/c8ra08402e extensively applied for the treatment of antibiotic wastewater. ${ }^{6}$ Ozone, as the conventionally powerful oxidant, has been conceived as a safe and clean oxidation technology. However, high energy demand and operation cost, low oxidation efficiency and selectivity towards organic substrates restrict its large-scale industrial applications. ${ }^{7}$ Combining ozone with the solid phase catalysts can accelerate the decomposition of ozone into hydroxyl radicals $(\cdot \mathrm{OH})$ and somehow overcome the limitations of ozonation alone. ${ }^{8}$ It has relatively low energy demand and high degradation and mineralization effectiveness of some refractory organic pollutants in waters, thus becoming a research hot spot in the field of ozone oxidation. ${ }^{7}$ So far, various solid catalysts have been reported including metal oxides, supported metals/metal oxides and some porous materials. ${ }^{9-16}$ Cobalt oxide is one of the highly reactive metal oxide as an ozonation catalyst. ${ }^{\mathbf{1 1}}$ In order to facilitate the separation of the cobalt oxide catalyst from water and provide more active sites on catalysts, some porous materials were used as supporters. Qi et al. ${ }^{7}$ reported that the catalytic ozonation of phenol using $\mathrm{Co}_{3} \mathrm{O}_{4} /$ nitrogen-doping graphene $\left(\mathrm{Co}_{3} \mathrm{O}_{4} / \mathrm{NG}\right)$ greatly improved the removal rate of the phenol. Hu et al. ${ }^{12}$ reported that cobalt oxide supported on mesoporous zirconia $\left(\mathrm{CoO}_{x} / \mathrm{MZ}\right)$ enhanced the mineralization of 2,4-D. Asma et al. ${ }^{13}$ studied that the catalytic ozonation of nitrobenzene using cobalt supported activated carbon catalyst (Co/OSAC) exhibited a high activity compare to ozone alone and OSAC. However, the 
carbon-based materials can generate large amount of sludge and is easily oxidized by ozone. ${ }^{17-19}$ In addition, the synthetic materials are high cost and may cause pollution problems to the environment. These disadvantages are the main limitation for the application of carbon-based materials and synthetic catalysts in the catalytic ozonation. ${ }^{20}$

In the present work, cobalt was modified on the natural and environmental-friendly mineral material (i.e., silicate ore) through efficient and simple impregnation method. Cobalt modified silicate ore was characterized by SEM-EDS, XRD, XPS, and BET, etc. The catalytic performance of CoSO in ozonation of TCH was investigated and the corresponding catalyzed ozonation mechanism was proposed. The influence of the catalyst preparation conditions were systematically studied. A series of experiments were designed to understand the degradation mechanism of TCH in the catalytic ozonization reactor. Furthermore, the stability and reusability of catalyst under optimum experimental conditions were also evaluated.

\section{Materials and methods}

\subsection{Chemicals}

The commercial tetracycline hydrochloride, with purity more than $\mathbf{9 8 . 0 \%}$, was purchased from Sigma-Aldrich. Physicochemical property of tetracycline hydrochloride ${ }^{1}$ was shown in Table $\mathrm{S} 1 . \dagger$ Cobaltous nitrate $\left(\mathrm{Co}\left(\mathrm{NO}_{3}\right)_{2} \cdot 6 \mathrm{H}_{2} \mathrm{O}\right)$ was purchased from Beijing chemical industry group Co., Ltd., China. Acetonitrile (HPLC Grade) were obtained from Shanghai Sinopharm Chemical Reagent Co. Ltd. (China). TBA (AR Grade, 99.9\%), $\mathrm{HClO}_{4}$ and $\mathrm{NaOH}$ were obtained from the Tianjin Ruijinte Chemical Reagent Co., Ltd. All chemicals were analytical grade. Silicate ore was obtained from Harbin Institute of Technology.

\subsection{Preparation and characterization of CoSO catalyst}

$\mathrm{Co}\left(\mathrm{NO}_{3}\right)_{2} \cdot 6 \mathrm{H}_{2} \mathrm{O}$ was used as Co source to prepare CoSO catalyst, which was prepared by incipient wetness impregnation. Detailed preparation process was as follows: first, the SO particles were washed with deionized water more than three times to remove surface dust, and then dried at $100{ }^{\circ} \mathrm{C}$ for $24 \mathrm{~h}$. The raw sample was grinded by a high-speed universal mill and then sieved to +60 to 40 mesh particle size fractions. Second, $5 \mathrm{~g}$ of crushed SO was soaked in $\mathrm{Co}\left(\mathrm{NO}_{3}\right)_{2} \cdot 6 \mathrm{H}_{2} \mathrm{O}$ solution $\left(0.5 \mathrm{~mol} \mathrm{~L}^{-1}, 100 \mathrm{~mL}\right)$, and use the water bath shock for $24 \mathrm{~h}$ keeping $30{ }^{\circ} \mathrm{C}$. After that, the suspension was precipitated and filtrated, which was then dried at $70{ }^{\circ} \mathrm{C}$ for $36 \mathrm{~h}$ before calcination treatment $\left(500{ }^{\circ} \mathrm{C}\right.$ for $5 \mathrm{~h}$ in air). After calcination, the prepared catalyst $\mathrm{CoSO}$ was cooled to room temperature and stored in a desiccator. Precursor $\left(\mathrm{Co}\left(\mathrm{NO}_{3}\right)_{2} \cdot 6 \mathrm{H}_{2} \mathrm{O}\right)$ solution concentration, calcination temperature and calcination time were investigate to optimize the preparation condition for CoSO catalyst.

Pores characteristics and specific surface area of CoSO were determined by $\mathrm{N}_{2}$ adsorption and desorption isotherms at $77 \mathrm{~K}$ on a Quantasorb surface area analyzer (ASAP-2020, Micromeritics, USA). The specific surface areas, pore volume and size of the materials were estimated by Brunauer-Emmett-Teller
(BET) method. The morphology of the samples was visualized by SEM-EDS (JSM-6490LV, Japan), and the catalyst surface was sputter coated with gold. X-ray diffraction (XRD) patterns of CoSO catalysts were characterized by a D/max-RA XRD instrument (Rigaku, Japan). The content of elements in CoSO catalyst was determined by X-ray photoelectron spectroscopy (XPS, Kratos-AXIS ULTRA DLD, Japan).

\subsection{Catalytic ozonation procedure}

Catalytic ozonation procedure was carried out in a semibatch mode by using the experimental installation shown in Fig. S1. $\dagger$ Ozone was produced in situ from dry air by a DHX-I laboratory ozone generator (Harbin Jiujiu Electrochemistry Technology, China). Ozone was immediately added into the solution through the microporous titanium diffuser after the addition of catalyst. The slurry was continuously stirred. In most cases, the initial TCH concentration, the ozone gas concentration, the ozone flow rate and the catalyst concentration were $30 \mathrm{mg} \mathrm{L}^{-1}$,

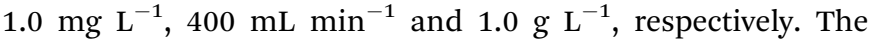
dissolved ozone concentration in water was measured by the indigo method. The gaseous ozone $1 \mathrm{mg} \mathrm{L}^{-1}$ was bubbled into the reactor to get $500 \mathrm{~mL}$ ozone saturated aqueous solution, and the concentration of ozone in the liquid phase was shown in Fig. S2. $\dagger$ The reaction temperature remained at $20{ }^{\circ} \mathrm{C}$. The initial $\mathrm{pH}$ of $\mathrm{TCH}$ solution was about 7.0 and regulated using $\mathrm{HClO}_{4}$ and $\mathrm{NaOH}$ solutions.

\subsection{Analysis methods}

The TCH samples were filtered through a Millipore filter $(0.22$ $\mu \mathrm{m})$, and then analyzed by means of a 1200 series highperformance liquid chromatography (HPLC, Agilent, USA) with a UV detector at $365 \mathrm{~nm}$ and XDB-C18 column $(4.6 \times 150$ $\mathrm{mm}, 5 \mu \mathrm{m})$. The mobile phase was acetonitrile and $0.01 \mathrm{~mol} \mathrm{~L}^{-1}$ aqueous oxalic acid (31:69, v/v) mixture at room temperature, with a constant flow rate of $1.0 \mathrm{~mL} \mathrm{~min}^{-1}$. The gas ozone concentration was measured by the iodometric method..$^{21}$ The dissolved ozone concentration in water was measured by the indigo method. ${ }^{22}$

After each reuse, the CoSO catalyst was washed with deionized water several times and dried $24 \mathrm{~h}$ at $100{ }^{\circ} \mathrm{C}$. The released cobalt ion was measured by inductively coupled plasma (ICP) on an OPTIMA 5300DV (PerkinElmer Co., USA). Total organic carbon (TOC) was determined by a Shimadzu TOC- $\mathrm{V}_{\mathrm{CPH}}$ analyzer. The point of zero charge $\left(\mathrm{pH}_{\mathrm{pzc}}\right)$ of CoSO catalyst was measured with a Zetasizer Nano (Malvern, UK).

\subsection{Synthesis of CoSO catalysts}

2.5.1 Effect of impregnation solution concentration on catalytic ozonation process. As shown in Fig. $\mathrm{S} 3, \uparrow$ the catalytic effect of CoSO was higher than that of SO. With the increase of impregnation concentration, the degradation efficiency of $\mathrm{TCH}$ increased firstly and then decreased. A maximum TCH degradation efficiency of $93.2 \%$ was obtained after 25 min of catalytic ozonation when the concentration of $\mathrm{Co}\left(\mathrm{NO}_{3}\right)_{3} \cdot 6 \mathrm{H}_{2} \mathrm{O}$ was $0.5 \mathrm{~mol} \mathrm{~L}^{-1}$. As shown in Table $\mathrm{S} 2, \uparrow$ when the concentrations of the impregnated liquid were $0.3,0.5,1.0$ and $1.5 \mathrm{~mol} \mathrm{~L}^{-1}$, the 
corresponding contents of Co of CoSO were 6.3, 11.2, 24.3 and $30.5 \%$, respectively. Besides that, the concentrations of leached cobalt ions in the solution after 25 min of catalytic ozonation were tested. The dissolution of cobalt ions was below the limit requirement in drinking water of China. ${ }^{29}$

Insufficient or excess $\mathrm{Co}_{3} \mathrm{O}_{4}$ loading content was not favorable for the catalytic activity. The possible reason for this phenomenon was that low metal oxide contents of CoSO would cause low catalytic activity while too much metal oxide contents would reduce the specific surface area of the CoSO. Moreover, $\mathrm{Co}_{3} \mathrm{O}_{4}$ on the surface of the $\mathrm{SO}$ was essential for catalytic ozonation. The dosage of $\mathrm{Co}_{3} \mathrm{O}_{4}$ obviously affected the pollutant degradation efficiency. It can promote ozone to rapidly decompose into $\cdot \mathrm{OH}^{11}$ But excess metal oxides would resulted in $\cdot \mathrm{OH}$ quenching. ${ }^{24}$ Therefore, the catalyst with a concentration of $0.5 \mathrm{~mol} \mathrm{~L}^{-1} \mathrm{Co}\left(\mathrm{NO}_{3}\right)_{3} \cdot 6 \mathrm{H}_{2} \mathrm{O}$ was prepared in the further experiments. The content of Co element in CoSO catalyst was $11.2 \%$ (denoted as $11.2 \% \mathrm{CoSO}$ ).

2.5.2 Effect of calcination temperature of $11.2 \%$ CoSO system on catalytic ozonation process. Calcination temperature had an important influence on the catalytic activity of the catalysts. As shown in Fig. S4, $\uparrow$ the calcination temperature of CoSO catalyst at $500{ }^{\circ} \mathrm{C}$ showed the highest catalytic activity. When the temperature increased from $200{ }^{\circ} \mathrm{C}$ to $500{ }^{\circ} \mathrm{C}$, the removal rate of $\mathrm{TCH}$ increased from $72.5 \%$ to $93.2 \%$. However, the activity of catalyst fell rapidly (84.6\% TCH removal rate), when calcination temperatures rised to $600{ }^{\circ} \mathrm{C}$. This was because excessive calcination temperature would destroy the pore structure and crystallinity of the catalyst, thus leading to the reduction of catalytic activity. Therefore, suitable calcination temperature was very important to the high activity catalyst. $500{ }^{\circ} \mathrm{C}$ was selected for the catalyst calcination temperature.

2.5.3 Effect of calcination time of $\mathbf{1 1 . 2 \%}$ CoSO system on catalytic ozonation process. CoSO catalyst was calcination at different time to investigate the effect of calcination time on CoSO performance. As presented in Fig. S5, $\dagger$ the catalytic activity of CoSO was the highest at $5 \mathrm{~h}$, and the removal rate of CIP was $93.2 \%$. In this study, catalysts prepared with different calcination times had little influence on the catalytic ozonation capacity for TCH. The subsequent experiments were prepared at calcination time of $5 \mathrm{~h}$.

\subsection{Investigation of $\mathbf{1 1 . 2 \%}$ CoSO system}

2.6.1 Physicochemical properties of $11.2 \%$ CoSO system. Fig. 1 displayed the X-ray powder diffraction patterns of the SO and CoSO. Compared with SO, the CoSO showed a series of different diffraction peaks. The diffraction peaks for the CoSO at $2 \theta=19.0^{\circ}, 31.2^{\circ}, 36.8^{\circ}, 44.8^{\circ}, 59.4^{\circ}$ and $65.3^{\circ}$ were assigned to planes (111), (220), (311), (400), (511) and (440) of $\mathrm{Co}_{3} \mathrm{O}_{4}$ (JCPDS no. 42-1467). ${ }^{25}$ It indicated that the $\mathrm{Co}_{3} \mathrm{O}_{4}$ particles were successfully loaded on the SO surface. ${ }^{26}$

SEM of the SO and CoSO samples were shown in Fig. S6. $\dagger$ Significant differences were found among the SO and CoSO. For the SO, the particle was relatively small and scattered in Fig. $\mathrm{S} 6(\mathrm{a}) \dagger$. After the cobalt modification, the particles of CoSO

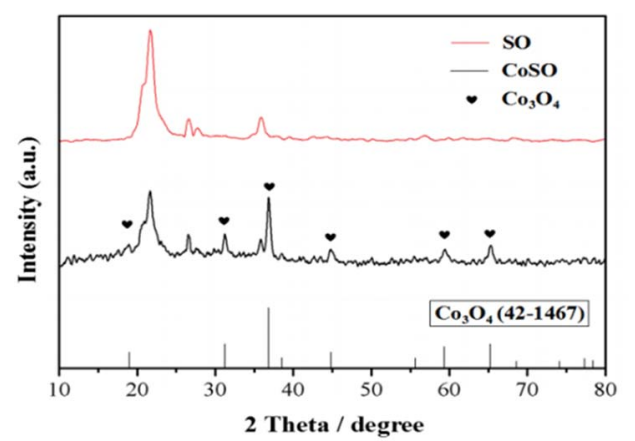

Fig. 1 X-ray powder diffraction patterns of SO and CoSO catalyst.

showed bigger size than SO in Fig. S6(b)†. The agglomeration of such particles may be caused by calcination.

EDS spectrum of SO, CoSO, and elemental mapping of the CoSO catalyst were shown in Fig. $\mathrm{S} 7, \dagger \mathrm{O}, \mathrm{Al}$ and $\mathrm{Si}$ were the domain elements in the natural SO with the ratio of 55.3, 3.3, and $39.4 \%$, respectively. The Co element was presence in the CoSO catalyst. $\mathrm{O}, \mathrm{Al}, \mathrm{Si}$ and Co were detected as the domain elements in the CoSO catalyst with the ratio of 51.7, 2.2, 34.9 and $11.2 \%$, respectively. Moreover, the Co element was evenly distributed on the surface of the SO (Fig. S7(f) $\dagger$ ). The results indicated that the Co element was successfully coated on the SO surface.

Fig. 2 revealed the surface chemical components of SO and CoSO materials. As shown in Fig. 2a, the characteristic peaks of the SO corresponded to Si 2p, C 1s and O 1s, while the characteristic peaks of the CoSO corresponded to Si 2p, C 1s, O 1s and Co 2p. It confirmed the presence of Co in the CoSO composites. Fig. 2b showed the Co 2p XPS spectrum of the synthesized catalyst. The two peaks had a peak separation of $15.0 \mathrm{eV}$ and binding energies at 794.8 and $779.8 \mathrm{eV}$, which correspond to the characteristic XPS peaks of $\mathrm{Co}_{3} \mathrm{O}_{4} \cdot{ }^{25,26}$ The O 1s region could be decomposed into four peaks (Fig. 3c), the peaks at $531.8 \mathrm{eV}$ and $532.4 \mathrm{eV}$ were assigned to surface adsorbed oxygen. The peak at $532.9 \mathrm{eV}$ was due to the
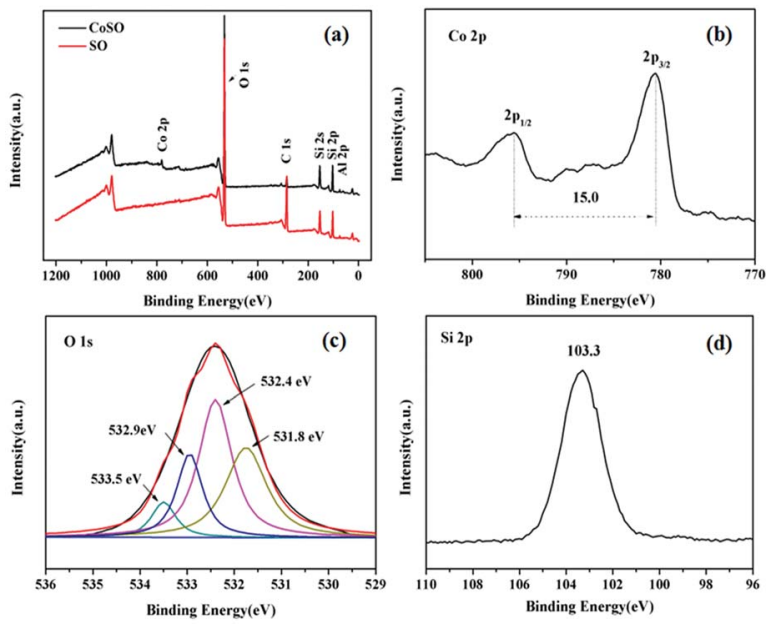

Fig. 2 XPS spectra analysis of the SO and CoSO catalyst. (a) Widerange scan of the SO and CoSO; (b) Co 2p, (c) O 1s and (d) Si 2p of the CoSO composites. 


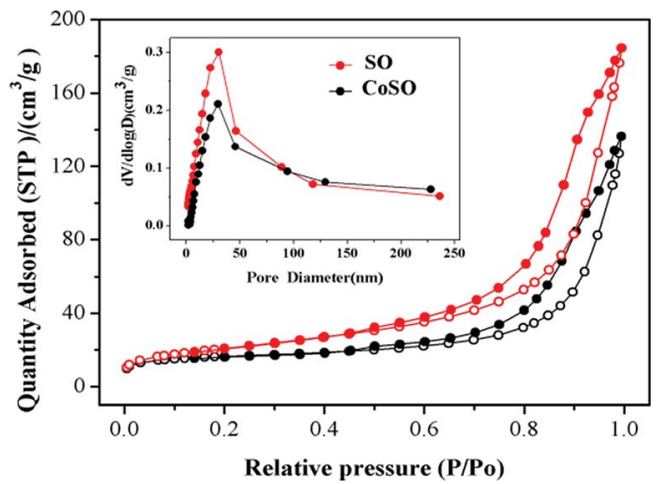

Fig. $3 \mathrm{~N}_{2}$ adsorption-desorption isotherms of the $\mathrm{SO}$ and CoSO.

chemically or physically adsorbed water, and 533.5 eV was likely associated with $\mathrm{Si}-\mathrm{O}-\mathrm{Si}^{27,28} \mathrm{Fig}$. $2 \mathrm{~d}$ showed the peak at $103.3 \mathrm{eV}$ corresponding to $\mathrm{Si} 2 \mathrm{p}^{29}$

The XPS results indicated that the presence of oxidized cobalt species as $\mathrm{Co}_{3} \mathrm{O}_{4}$ in the CoSO catalyst. It was consistent with the XRD patterns (Fig. 1).

The pore size distributions and $\mathrm{N}_{2}$ adsorption-desorption isotherms of both SO and CoSO were shown in Fig. 3. Two samples exhibited adsorption-desorption isotherms identified as typical type IV with hysteresis loops, which means that the SO and CoSO catalyst had mesoporous structures. ${ }^{29}$ The data concerning their BET, pore volume and average pore size were listed in Table 1. The specific surface areas of the SO and CoSO were 75 and $57 \mathrm{~m}^{2} \mathrm{~g}^{-1}$, respectively. The results illustrate that the modification of SO by cobalt decreased its specific surface area, pore volume and average pore size. This may be that the cobalt oxide dispersed into the pores of the SO and the agglomeration of CoSO particles during the sintering process (as Fig. S5 $\dagger$ ).

\subsubsection{Catalytic properties of $\mathbf{1 1 . 2 \%}$ CoSO system}

Influence of initial $\mathrm{pH}$. Influence of initial $\mathrm{pH}$ on TCH and TOC removal in the processes of ozonation alone and CoSO catalytic ozonation, respectively, were exhibited in Fig. 4. As shown in Fig. 4a, the removal efficiency of TCH by ozonation alone increased significantly with the increase of initial solution $\mathrm{pH}$. This could be due to that the $\mathrm{pH}$ increase promoted the decomposition of ozone to produce $\cdot \mathrm{OH} \cdot{ }^{30}$ The decomposition of $\mathrm{O}_{3}$ occurs as followings:

$$
\begin{aligned}
& \mathrm{O}_{3}+\mathrm{OH}^{-} \rightarrow \mathrm{O}_{2}^{\cdot-}+\mathrm{HO}_{2}{ }^{\cdot} \\
& \mathrm{O}_{3}+\mathrm{HO}_{2}{ }^{-} \rightarrow 2 \mathrm{O}_{2}+\cdot \mathrm{OH}
\end{aligned}
$$

As for $\mathrm{O}_{3}$ alone, $\mathrm{O}_{3}$ was the main oxidant at initial $\mathrm{pH}$ of 3, which led to lower TCH degradation. However, when the initial

Table 1 BET of the SO and MnSO

\begin{tabular}{llll}
\hline Sample & BET $\left(\mathrm{m}^{2} \mathrm{~g}^{-1}\right)$ & $\begin{array}{l}\text { Pore volume } \\
\left(\mathrm{cm}^{3} \mathrm{~g}^{-1}\right)\end{array}$ & $\begin{array}{l}\text { Average pore } \\
\text { size }(\mathrm{nm})\end{array}$ \\
\hline SO & 75 & 0.24 & 12.95 \\
CoSO & 57 & 0.17 & 11.90
\end{tabular}
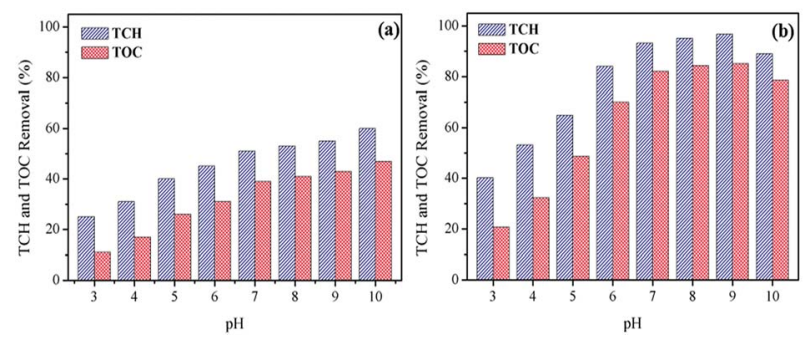

Fig. $4 \mathrm{pH}$ influence on $\mathrm{TCH}$ degradation and TOC removal in ozonation alone (a) and CoSO catalytic ozonation (b) process. Initial $\mathrm{TCH}=$ $30 \mathrm{mg} \mathrm{L}^{-1} ; \mathrm{T}=20^{\circ} \mathrm{C}$; gaseous ozone $=1.0 \mathrm{mg} \mathrm{L}^{-1}$; catalyst $=1.0 \mathrm{~g} \mathrm{~L}^{-1}$.

$\mathrm{pH}$ increased from 7 to 10 , both $\mathrm{O}_{3}$ (oxidation potential $2.07 \mathrm{eV}$ ) and $\cdot \mathrm{OH}$ (higher oxidation potential $2.8 \mathrm{eV}$ ) were the predominant oxidants, thus causing more TCH degradation. Compared to $\mathrm{O}_{3}$ alone, the degradation rate of $\mathrm{TCH}$ had been obviously improved in CoSO catalytic ozonation system. The degradation rate of $\mathrm{TCH}$ reached $53.2 \%$ significantly higher than $32.1 \%$ with $\mathrm{O}_{3}$ alone at $\mathrm{pH}$ 4. This indicated that the catalyst CoSO can efficiently induce the decomposition of ozone to produce $\cdot \mathrm{OH}$, which was difficult to decompose under low pH. The TCH degradation rates were more than $93.2 \%$ at $\mathrm{pH}$ from 7 to 9 in $\mathrm{CoSO} / \mathrm{O}_{3}$ system. This showed that the $\mathrm{CoSO} / \mathrm{O}_{3}$ system had excellent catalytic effect, and the catalyst promoted the decomposition of ozone to produce $\cdot \mathrm{OH}$ and effectively enhanced the $\mathrm{TCH}$ degradation. Correspondingly, the TOC removal rate increased with initial $\mathrm{pH}$ increasing in $\mathrm{O}_{3}$ alone, and the maximum TOC removal was only $47.5 \%$ (Fig. $4 \mathrm{a}$ ). In comparison, TOC removal rates at all $\mathrm{pH}$ conditions were greatly higher in CoSO catalytic ozonization (Fig. 4b). It should be noticed that, when the initial $\mathrm{pH}$ of the solution increased from 9 to 10, the TCH and TOC removal rates decreased in $\mathrm{CoSO} / \mathrm{O}_{3}$. This phenomenon could be due to the following two reasons: (i) the excessively generated $\cdot \mathrm{OH}$ reacted with each other; (ii) $\cdot \mathrm{OH}$ reacted with hydroperoxyl $\left(\mathrm{HO}_{2}{ }^{\circ}\right)$ free radical generated during $\mathrm{O}_{3}$ decomposition. ${ }^{24}$ The two mainly reactions were as follows:

$$
\begin{gathered}
\cdot \mathrm{OH}+\cdot \mathrm{OH} \rightarrow \mathrm{H}_{2} \mathrm{O}_{2} \\
\mathrm{HO}_{2}^{\cdot}+\cdot \mathrm{OH} \rightarrow \mathrm{H}_{2} \mathrm{O}+\mathrm{O}_{2}
\end{gathered}
$$

TCH can be positively charged, zwitterionic or negatively charged under different $\mathrm{pH}$ conditions with three $\mathrm{pKa}$ values $(\sim 3.3, \sim 7.7$ and $\sim 9.7)$. At low $\mathrm{pH}, \mathrm{TCH}$ was fully protonated into $\mathrm{TCH}^{3+}$. With the increase of $\mathrm{pH}$, deprotonation reactions took place in three steps, where $\mathrm{TCH}_{2}, \mathrm{TCH}^{-}$and $\mathrm{TCH}^{2-}$ increased. ${ }^{31}$ Generally, the dissociation degree and deprotonation of $\mathrm{TCH}$ increased with $\mathrm{pH}$ increase, which contributed to its affinity reaction with $\mathrm{O}_{3} \cdot{ }^{32}$ Therefore, the $\mathrm{TCH}$ removal rate increased accordingly in Fig. 4.

The surface charge of metal oxide was largely determined by its hydroxyl groups. ${ }^{33}$ The catalyst becomes protonated or deprotonated depending on the solution pH below or above the $\mathrm{pH}_{\mathrm{pzc}}$ as follows: $:^{34}$ 


$$
\begin{gathered}
\mathrm{M}-\mathrm{OH}+\mathrm{H}^{+} \Leftrightarrow \mathrm{M}-\mathrm{OH}_{2}^{+} \mathrm{pH}<\mathrm{pH}_{\mathrm{pzc}} \\
\mathrm{M}-\mathrm{OH}+\mathrm{OH}^{-} \Leftrightarrow \mathrm{M}-\mathrm{O}^{-}+\mathrm{H}_{2} \mathrm{O} \mathrm{pH}>\mathrm{pH}_{\mathrm{pzc}}
\end{gathered}
$$

The $\mathrm{pH}_{\mathrm{pzc}}$ of prepared CoSO was 7.97. It was deprotonated and negatively charged in aqueous solution at $\mathrm{pH}>7.97$. As reported by Chen et al., ${ }^{24}$ negatively charged surface had a strong reactivity toward ozone, which contributed to the ozone oxidation. In the present study, the optimum solution $\mathrm{pH}$ was 9. The removal efficiency of TCH and TOC at $\mathrm{pH} 9.0$ was only a little higher than that at $\mathrm{pH}$ 7.0. Therefore, in order to make the reaction system convenient and simple to operate, the further catalytic ozonation experiments were conducted at $\mathrm{pH}$ 7.0.

Influence of TCH initial concentration. As shown in Fig. 5a, the degradation of $\mathrm{TCH}$ decreased remarkably with initial $\mathrm{TCH}$ ranged at $5-50 \mathrm{mg} \mathrm{L^{-1 }}$ in the $\mathrm{CoSO} / \mathrm{O}_{3}$ system. Same trend showed in Fig. 5b that the TOC removal efficiency decreased with the increase of initial TCH concentration. This indicated that the initial concentration had a negative effect on TCH and TOC removal. Obviously, due to the same quantity of CoSO catalysts in catalytic ozonation process, the number of active sites on the CoSO catalysts surface remain stable. Therefore, low-concentration TCH would be degraded quickly. Furthermore, the surface activities of CoSO might decrease due to the adsorption of TCH or its intermediate products as initial $\mathrm{TCH}$ concentration increasing, thus leading to the decrease of $\mathrm{TCH}$ and TOC removal. ${ }^{35,36}$

Influence of reaction temperature. The reaction temperature was an important factor for TCH degradation, which influenced the ozone solubility and reaction rate in aqueous solution. ${ }^{37}$ Fig. 6 presented the influence of reaction temperature $(5,10,20$ and $35{ }^{\circ} \mathrm{C}$ ) on catalytic ozonation activity of CoSO for of $\mathrm{TCH}$ degradation. As shown in Fig. 7, TCH removal efficiency slightly increased, while TOC removal significantly increased from $37.6 \%$ to $82.1 \%$ with temperature increasing from $5{ }^{\circ} \mathrm{C}$ to $20{ }^{\circ} \mathrm{C}$ at $120 \mathrm{~min}$. However, TCH and TOC removal were reduced when the temperature further increased to $35{ }^{\circ} \mathrm{C}$. Increase reaction temperature can produce higher chemical reaction rate constant and improve the TCH degradation, ${ }^{38}$ while ozone solubility in water would decrease with temperature increasing. ${ }^{27}$ Therefore, $20{ }^{\circ} \mathrm{C}$ was selected as the optimal reaction temperature for catalytic ozonation of $\mathrm{TCH}$ over CoSO.

Influence of catalyst concentration. As shown in Fig. 7, the TCH removal efficiency increased from $46.7 \%$ to $93.9 \%$ at $25 \mathrm{~min}$ and TOC removal efficiency from $39.2 \%$ to $83.2 \%$ with catalyst
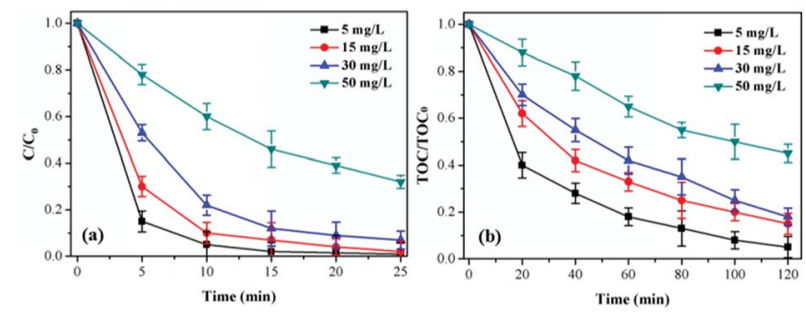

Fig. 5 Influence of initial TCH concentration on $\mathrm{TCH}$ degradation and TOC removal. Initial $\mathrm{pH}=7.0 ; \mathrm{T}=20^{\circ} \mathrm{C}$; gaseous ozone $=1.0 \mathrm{mg} \mathrm{L}^{-1}$; catalyst $=1.0 \mathrm{~g} \mathrm{~L}^{-1}$.
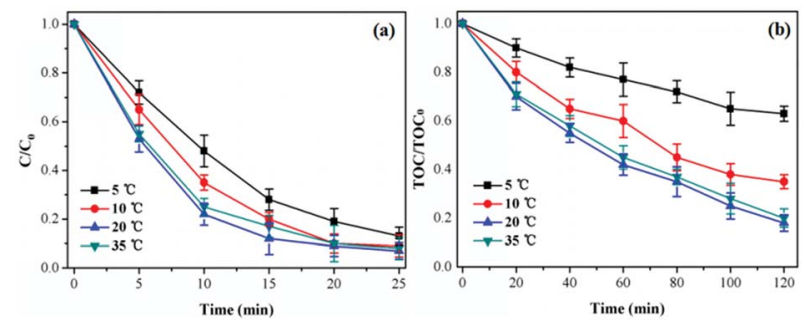

Fig. 6 Influence of reaction temperature on $\mathrm{TCH}$ degradation and TOC removal. Initial $\mathrm{pH}=7.0$; initial $\mathrm{TCH}=30 \mathrm{mg} \mathrm{L}^{-1}$; gaseous ozone $=1.0 \mathrm{mg} \mathrm{L}^{-1}$; catalyst $=1.0 \mathrm{~g} \mathrm{~L}^{-1}$.

concentration increasing from $0.0 \mathrm{~g} \mathrm{~L}^{-1}$ to $1.5 \mathrm{~g} \mathrm{~L}^{-1}$. The increasing of catalyst concentration was conducive to improve the specific surface area and active sites thus accelerating $\mathrm{O}_{3}$ decomposition and generating more $\cdot \mathrm{OH}$. This would increase the removal efficiency of TCH and TOC. ${ }^{39}$ However, the TCH (TOC) removal efficiency only increased $0.7 \%(1.1 \%)$ when the catalyst concentration increased from $1.0 \mathrm{~g} \mathrm{~L}^{-1}$ to $1.5 \mathrm{~g} \mathrm{~L}^{-1}$ due to the limited amount of $\mathrm{O}_{3}$ in the catalytic ozonation reaction system. ${ }^{9}$ Considering the treatment cost, $1.0 \mathrm{~g} \mathrm{~L}^{-1}$ was chosen as the catalyst concentration in the following experiments.

Catalyst stability and reusability of $11.2 \%$ CoSO system. Considering the industrial application of the CoSO catalysts, it is essential to maintain the high catalytic activity, stable structure and lower metal ions leaching for long operation times. The CoSO catalysts were reused seven times to examine their stability performances for the TCH degradation. As shown in Fig. 8, the TCH degradation had no obvious deactivation with the increase of using times. The TCH removal efficiency remain almost unchanged throughout seven successive runs. Besides that, the concentrations of leached cobalt ions from the CoSO into the solution after $25 \mathrm{~min}$ of catalytic ozonation was below $0.015 \mathrm{mg} \mathrm{L}^{-1}$. The leached ion concentration meets the Integrated Wastewater Discharge Standard in China. ${ }^{23}$ The results indicated that the CoSO catalyst had an excellent long-term stability.

\subsection{Possible reaction mechanism during CoSO catalytic ozonation process}

2.7.1 Comparison of TCH and TOC removal among different processes. Fig. 9 shows the comparison of $\mathrm{TCH}$ and TOC removal among ozonation alone, SO adsorption, CoSO adsorption, $\mathrm{SO} / \mathrm{O}_{3}$ and $\mathrm{CoSO} / \mathrm{O}_{3}$ processes. As shown in Fig. 9a, the adsorptions of $\mathrm{TCH}$ by SO and CoSO were about $27.3 \%$ and
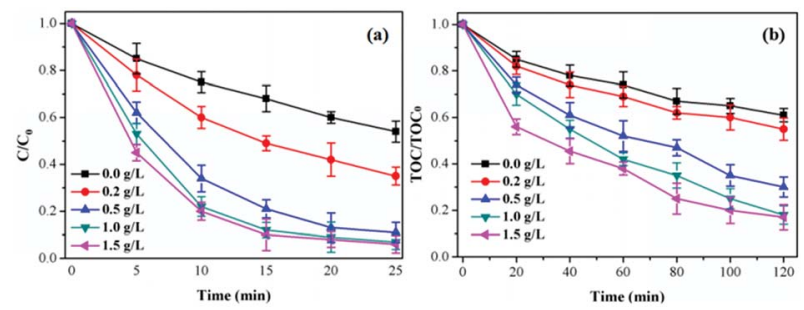

Fig. 7 Influence of catalyst concentration on $\mathrm{TCH}$ degradation and TOC removal. Initial $\mathrm{pH}=7.0$; initial $\mathrm{TCH}=30 \mathrm{mg} \mathrm{L}^{-1} ; \mathrm{T}=20^{\circ} \mathrm{C}$; gaseous ozone $=1.0 \mathrm{mg} \mathrm{L}^{-1}$. 


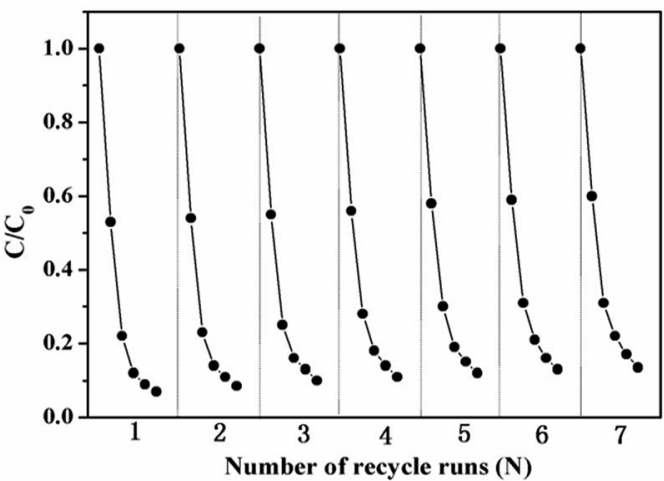

Fig. $8 \mathrm{TCH}$ removal during multicycle degradation of $\mathrm{TCH}$ over $\mathrm{CoSO}$ with ozone. Initial $\mathrm{pH}=7.0$; initial $\mathrm{TCH}=30 \mathrm{mg} \mathrm{L}{ }^{-1} ; \mathrm{T}=20{ }^{\circ} \mathrm{C}$; gaseous ozone $=1.0 \mathrm{mg} \mathrm{L}^{-1}$; catalyst $=1.0 \mathrm{~g} \mathrm{~L}^{-1}$.

$24.7 \%$ in equilibrium. The adsorption of $\mathrm{TCH}$ on CoSO was slightly lower than that on SO. This may be due to the reduction of the pore volume and surface area which were confirmed by textural analysis (Table 1). The presence of CoSO enhanced the removal rate of $\mathrm{TCH}$ and TOC by ozonation compared to other processes (Fig. 9a and b). The addition of CoSO promoted the removal of $\mathrm{TCH}$ from $46 \%$ to $93.2 \%$ in $25 \mathrm{~min}$, as compared with ozone alone. The degradation efficiency of TCH using CoSO catalyst was significantly higher than that using SO. As shown in Fig. 9b, only $39.1 \%$ and $55.5 \%$ of TOC were removed with ozone alone and $\mathrm{SO} / \mathrm{O}_{3}$ respectively, while $82.1 \%$ of TOC were removed in $\mathrm{CoSO} / \mathrm{O}_{3}$ system which was higher than the results reported by Pacheco et al. ${ }^{3}$ and Khan et al. ${ }^{32}$ The results indicated that the presence of Co species contributed to the higher activity of CoSO for catalysis-oxidation degradation of $\mathrm{TCH}^{40}$ To study the kinetics of these ozone oxidation processes, the experimental data of TCH degradation and mineralization were fitted to an apparent first-order kinetics $\left(R^{2}>0.97\right)$. And the results were shown in Table $\mathrm{S} 3 . \dagger$ The TCH degradation rate constant with $\mathrm{CoSO} / \mathrm{O}_{3}$ was respectively 2.29 times and 4.58 times higher than that with $\mathrm{SO} / \mathrm{O}_{3}$ and $\mathrm{O}_{3}$ alone. As observed, the rate constant of $\mathrm{TCH}$ mineralization in $\mathrm{CoSO} / \mathrm{O}_{3}$ process was $0.014 \mathrm{~min}^{-1}, 3.5$ and 2.0 times higher than that of $\mathrm{O}_{3}$ alone and $\mathrm{SO} / \mathrm{O}_{3}$ processes respectively.

In general, CoSO had an excellent catalytic activity on both $\mathrm{TCH}$ and TOC removal. In addition, the adsorption property of the catalyst also promoted TCH degradation and mineralization. However, the TOC removal rate was only $82.1 \%$ at 120
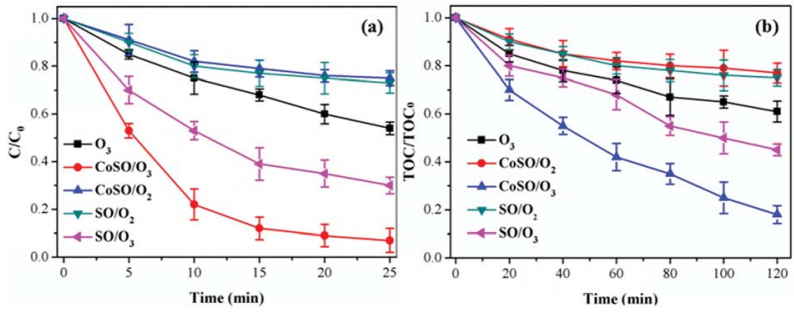

Fig. 9 Comparison of $\mathrm{TCH}$ and $\mathrm{TOC}$ removal among different processes. Initial $\mathrm{pH}=7.0$; initial $\mathrm{TCH}=30 \mathrm{mg} \mathrm{L}^{-1} ; \mathrm{T}=20^{\circ} \mathrm{C}$; gaseous ozone $=1.0 \mathrm{mg} \mathrm{L}^{-1}$; catalyst $=1.0 \mathrm{~g} \mathrm{~L}^{-1}$. minutes, which was significantly less than the removal efficiency of the TCH. This result was because TCH was degraded into a large number of intermediates during ozone oxidation, which were difficult to oxidize completely and quickly.

2.7.2 CoSO catalytic ozonation mechanism. In order to study whether $\mathrm{TCH}$ degradation in the $\mathrm{CoSO} / \mathrm{O}_{3}$ process involves $\cdot \mathrm{OH}$ mechanism, $50 \mathrm{mg} \mathrm{\textrm {L } ^ { - 1 }}$ TBA (tert-butyl alcohol) was added in the CoSO catalytic ozonation system at different treatment time $(0,5$ and $10 \mathrm{~min})$. TBA is a strong hydroxyl radical scavenger. It reacts rapidly with $\cdot \mathrm{OH}$ with a rate constant of $6.0 \times 10^{8} \mathrm{M}^{-1} \mathrm{~s}^{-1}$ and only $3.0 \times 10^{-3} \mathrm{M}^{-1} \mathrm{~s}^{-1}$ with $\mathrm{O}_{3}{ }^{40}$ As shown in Fig. S9, $\uparrow$ The TCH removal with TBA was obviously lower than that with no TBA addition, which indicated the existence of $\cdot \mathrm{OH}$. When TBA was added at 0,5 and $10 \mathrm{~min}$, the removal of TCH after $25 \mathrm{~min}$ reduced by 53\%, 30\% and 10\%, respectively. When the TBA was added at 10 minutes, the inhibition of $\mathrm{TCH}$ degradation by TBA addition was not obvious. This phenomenon can be explained that the degradation of $\mathrm{TCH}$ by $\cdot \mathrm{OH}$ oxidation generally occurred in the initial short time (less than $10 \mathrm{~min}$ ) where the TCH inhibition predominated. ${ }^{41}$ The results in Fig. S9† showed that TCH degradation mainly followed the mechanism of hydroxyl radical oxidation. In the process of catalytic ozonization, $\cdot \mathrm{OH}$ played a dominant role in the oxidation. TCH was still degraded in the addition the TBA inhibitor which can inhibit the production of - $\mathrm{OH}$. This indicated the existence of direct oxidation by ozone.

In catalytic ozonation process, surface hydroxyl groups on the catalyst surface would facilitate the ozone decomposition. In addition, ozone could be adsorbed on the catalyst surface due to its electrophilic character which promotes the ozone decomposition and the generation of $\cdot \mathrm{OH}^{.2}$ As shown in Fig. $\mathrm{S} 10, \uparrow$ the addition of $\mathrm{H}_{2} \mathrm{O}_{2}$ significantly improved the $\mathrm{TCH}$ degradation by ozone, which can promote ozone decomposition to generate more reactive $\cdot \mathrm{OH}$. The $\mathrm{H}_{2} \mathrm{O}_{2}$ experiment further supported our proposed mechanism. In our experiment, the $\mathrm{pH}_{\mathrm{pzc}}$ of CoSO was 7.97, it was protonated and positively charged in aqueous solution at $\mathrm{pH}<7.97$. In addition, when the $\mathrm{pH}$ was more than $7.7\left(\mathrm{pK}_{\mathrm{a}_{2}}\right)$ the majority of TCH molecules in solution were in the form of anion. ${ }^{43}$ When the solution $\mathrm{pH}$ located between $\mathrm{pK}_{\mathrm{a}_{2}}$ and $\mathrm{pH}_{\mathrm{pzc}}$, it would enhance the adsorption between negatively charged TCH and positively charged CoSO catalysts. As shown in Fig. 4, TCH had a high degradation rate when $\mathrm{pH}$ value was between 7 and 9. This indicated that oxidation reaction of TCH took place on the surface of catalyst to some extent. In addition, TBA was hardly adsorbed on the surface of catalysts, ${ }^{43}$ and the addition of TBA could effectively inhibit the TCH oxidation through bulk reactions instead of that on catalyst surface. TCH was still decomposed in the addition of TBA indicating that its oxidation also occurred on catalyst surface. Overall, the degradation of TCH with CoSO could be attributed to a synergistic mechanism that combines TCH oxidation at the surface of catalyst as well as in the bulk liquid phase (As shown in Fig. 10). Simultaneously, it was illustrated in the formula (7)-(12).

(I) Catalyst surface reaction:

(a) Indirect (radical) reactions 


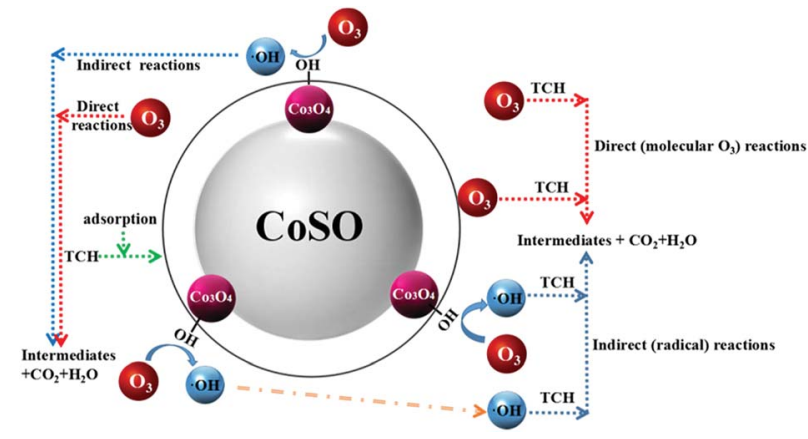

Fig. 10 Reaction mechanism of the CoSO process.

$$
\begin{aligned}
& \mathrm{CoSO}^{-\cdot \mathrm{OH}}+\mathrm{TCH} \rightarrow \mathrm{CoSO}+\mathrm{CO}_{2}+\mathrm{H}_{2} \mathrm{O}+\text { intermediates (7) } \\
& \mathrm{CoSO}^{-\mathrm{TCH}}+\cdot \mathrm{OH} \rightarrow \mathrm{CoSO}+\mathrm{CO}_{2}+\mathrm{H}_{2} \mathrm{O}+\text { intermediates (8) }
\end{aligned}
$$

(b) Direct (molecular $\mathrm{O}_{3}$ ) reactions

$$
\begin{aligned}
& \mathrm{CoSO}^{-\mathrm{O}_{3}}+\mathrm{TCH} \rightarrow \mathrm{CoSO}+\mathrm{CO}_{2}+\mathrm{H}_{2} \mathrm{O}+\text { intermediates } \\
& \mathrm{CoSO}-\mathrm{TCH}+\mathrm{O}_{3} \rightarrow \mathrm{CoSO}+\mathrm{CO}_{2}+\mathrm{H}_{2} \mathrm{O}+\text { intermediates }
\end{aligned}
$$

(II) Bulk solution reaction:

(a) Indirect (radical) reactions

$$
\mathrm{TCH}+\cdot \mathrm{OH} \rightarrow \text { intermediates }+\mathrm{CO}_{2}+\mathrm{H}_{2} \mathrm{O}
$$

(b) Direct (molecular $\mathrm{O}_{3}$ ) reactions

$$
\mathrm{TCH}+\mathrm{O}_{3} \rightarrow \text { intermediates }+\mathrm{CO}_{2}+\mathrm{H}_{2} \mathrm{O}
$$

\section{Conclusions}

In this study, natural silicate ore as a catalyst support was modified through immobilization of cobalt metal oxide using incipient wetness impregnation method. The CoSO catalyst with impregnation concentration of $0.5 \mathrm{~mol} \mathrm{~L}^{-1}$, calcination temperature at $500{ }^{\circ} \mathrm{C}$ and calcination time at $5 \mathrm{~h}$ showed the best performance on ozonation of $\mathrm{TCH}$. Compared to the $\mathrm{O}_{3}$ alone and $\mathrm{SO} / \mathrm{O}_{3}$ process, the presence of CoSO obviously improved the degradation and mineralization efficiency of TCH. The TCH and TOC removal in ozone oxidation process followed apparent firstorder kinetics. The presence of TBA significantly inhibits TCH degradation indicating that the oxidation mechanism of $\mathrm{TCH}$ occured via hydroxyl radical. The catalyst activity of CoSO on $\mathrm{TCH}$ and TOC removal slightly decreased with used cycle increasing. In general, the CoSO catalyst has great application potential to remove antibiotic wastewater because of its excellent catalytic activity, good stability and low cost.

\section{Conflicts of interest}

There are no conflicts to declare.

\section{Acknowledgements}

This work was financially supported by the Fundamental Research Funds for the Central Universities (Grant No. HIT. NSRIF.2019047), the China Postdoctoral Science Special Foundation (No. 2018T110304) and Heilongjiang Postdoctoral Fund (No. LBH-Z17059).

\section{References}

1 H. Xiong, S. Dong, J. Zhang, D. Zhou and B. E. Rittmann, Water Res., 2018, 136, 75.

2 Y. Wang, H. Zhang, J. Zhang, C. Lu, Q. Huang, J. Wu and F. Liu, J. Hazard. Mater., 2011, 192, 35.

3 C. Pacheco, M. Polo, J. Utrilla and J. PeNalver, Chem. Eng. J., 2011, 178, 115.

4 I. Dalmázio, M. Almeida and R. Augusti, J. Am. Soc. Mass Spectrom., 2007, 18, 679.

5 H. Xiong, D. Zou, D. Zhou, S. Dong, J. Wang and B. E. Rittmannd, Chem. Eng. J., 2017, 316, 7.

6 L. Hou, H. Zhang, L. Wang and L. Chen, Chem. Eng. J., 2013, 229, 577.

7 Q. Bao, K. S. Hui and J. G. Duh, J. Environ. Sci., 2016, 50, 38. 8 L. Luo, D. Zou, D. Lu, B. Xin, M. Zhou, X. Zhai and J. Ma, RSC $A d v ., 2018,8,33534$.

9 L. Gang, Y. Lu, L. Cheng, M. Zhu, C. Zhai, Y. Du and P. Yang, J. Hazard. Mater., 2015, 294, 201.

10 M. Fathinia, A. Khataee, S. Aber and A. Naseri, Appl. Catal., B, 2016, 184, 270.

11 Y. Dong, K. He, L. Yin and A. Zhang, Nanotechnology, 2007, 18, 435602.

12 C. Hu, S. Xing, A. Jiuhui Qu and H. He, J. Phys. Chem., 2008, 112, 5978.

13 A. Abdedayem, M. Guiza, F. J. R. Toledo and A. Ouederni, Sep. Purif. Technol., 2017, 184, 308.

14 H. Einaga, N. Maeda, S. Yamamoto and Y. Teraoka, Catal. Today, 2015, 245, 22.

15 F. Rezaei, G. Moussavi, A. R. Bakhtiari and Y. Yamini, J. Hazard. Mater., 2016, 306, 348.

16 A. Ikhlaq, D. R. Brown and B. Kasprzyk-Hordern, Appl. Catal., B, 2012, 123, 94.

17 R. Huang, H. Yan, L. Li, D. Deng, Y. Shu and Q. Zhang, Appl. Catal., B, 2011, 106, 264.

18 X. Lu, Q. Zhang, W. Yang, X. Li, L. Zeng and L. Li, RSC Adv., 2015, 5, 10537.

19 F. Qi, B. Xu, L. Zhao, Z. Chen, L. Zhang, D. Sun and J. Ma, Appl. Catal., B, 2012, 121-122, 171.

20 G. Moussavi, R. Khosravi and N. R. Omran, Appl. Catal., A, 2012, 445-446, 42.

21 K. Rakness, G. Gordon, B. Langlais, W. Masschelein, N. Matsumoto, Y. Richard, C. M. Robson and I. Somiya, Ozone: Sci. Eng., 1996, 18, 209.

22 H. Bader and J. Hoigné, Water Res., 1981, 15, 449.

23 B. Reddy, B. Chowdhury and P. G. Smirniotis, Appl. Catal., A, 2001, 211, 19.

24 W. Chen, X. Li, Z. Pan, S. Ma and L. Li, Chem. Eng. J., 2016, 304, 594. 
25 L. Fu, Z. M. Liu, Y. Q. Liu, B. X. Han, P. G. Hu, L. C. Cao and D. B. Zhu, Adv. Mater., 2005, 17, 217.

26 C. W. Kung, H. W. Chen, C. Y. Lin, R. Vittal and K. C. Ho, J. Power Sources, 2012, 214, 91.

27 X. Tan, Y. Wan, Y. Huang, C. He, Z. Zhang, Z. He, L. Hu, J. Zeng and D. Shu, J. Hazard. Mater., 2017, 321, 162.

28 Y. Nie, C. Hu, N. Li, L. Yang and J. Qu, Appl. Catal., B, 2014, 147, 287.

29 H. Yan, P. Lu, Z. Pan, X. Wang, Q. Zhang and L. Li, J. Mol. Catal. A: Chem., 2013, 377, 57.

30 Y. Guo, B. Xu and F. Qi, Chem. Eng. J., 2016, 287, 381.

31 Y. Wang, H. Zhang, J. Zhang, C. Lu, Q. Huang, J. Wu and F. Liu, J. Hazard. Mater., 2011, 192, 35.

32 M. Khan, H. Bae and J. Jung, J. Hazard. Mater., 2010, 181, 659.

33 B. Kasprzyk-Hordern, M. Ziółek and J. Nawrocki, Appl. Catal., B, 2003, 46, 639.

34 L. Zhao, Z. Sun, J. Ma and H. Liu, Environ. Sci. Technol., 2009, 43, 2047.
35 Z. Q. Liu, J. Tu, Q. Wang, Y. H. Cui, L. Zhang, L. Zhang, X. Wu, B. Zhang and J. Ma, Sep. Purif. Technol., 2018, 200, 51.

36 Y. Ren, H. Zhang, H. An, Y. Zhao, J. Feng, L. Xue, T. Luan and

Z. Fan, J. Colloid Interface Sci., 2018, 256, 347.

37 L. Zhao, J. Ma, Z. Sun and X. Zhai, Appl. Catal., B, 2008, 83, 256.

38 R. Huang, B. Lan, Z. Chen, H. Yan, Q. Zhang, J. Bing and L. Li, Chem. Eng. J., 2012, 180, 19.

39 Y. Huang, W. Xu, L. Hu, J. Zeng, C. He, X. Tan, Z. He, Q. Zhang and D. Shu, Catal. Today, 2017, 297, 143.

40 A. Abdedayem, M. Guiza, F. J. R. Toledo and A. Ouederni, Sep. Purif. Technol., 2017, 184, 308.

41 G. Moussavi, A. Khavanin and R. Alizadeh, Appl. Catal., B, 2010, 97, 160.

42 S. P. Ghuge and A. K. Saroha, J. Environ. Manage., 2018, 211, 83.

43 Z. Hopkins and L. Blaney, Sci. Total Environ., 2014, 468, 337. 